\title{
I Cannot See You-The Perspectives of Deaf Students to Online Learning during COVID-19 Pandemic: Saudi Arabia Case Study
}

\author{
Wajdi Aljedaani ${ }^{1, *(D)}$, Mona Aljedaani ${ }^{2}$, Eman Abdullah AlOmar ${ }^{3}\left(\mathbb{D}\right.$, Mohamed Wiem Mkaouer $^{3, *(D)}$, \\ Stephanie Ludi ${ }^{1}$ and Yousef Bani Khalaf ${ }^{4}$
}

check for updates

Citation: Aljedaani, W.; Aljedaani, M.; AlOmar, E.A.; Mkaouer, M.W.; Ludi, S.; Khalaf, Y.B. I Cannot See You-The Perspectives of Deaf Students to Online Learning during COVID-19 Pandemic: Saudi Arabia Case Study. Educ. Sci. 2021, 11, 712 https://doi.org/10.3390/

educsci11110712

Academic Editor: Kelum Gamage

Received: 27 August 2021

Accepted: 28 October 2021

Published: 5 November 2021

Publisher's Note: MDPI stays neutral with regard to jurisdictional claims in published maps and institutional affiliations.

Copyright: (c) 2021 by the authors. Licensee MDPI, Basel, Switzerland This article is an open access article distributed under the terms and conditions of the Creative Commons Attribution (CC BY) license (https:// creativecommons.org/licenses/by/ $4.0 /)$
1 Department of Computer Science and Engineering, University of North Texas, Denton, TX 76203, USA; Stephanie.Ludi@unt.edu

2 Department of European Languages and Literature, King Abdulaziz University, Jeddah 21589, Saudi Arabia; Mona.m.aljedaani@hotmail.com

3 Department of Software Engineering, Rochester Institute of Technology, Rochester, NY 14623, USA; eaa6167@rit.edu

4 Special Technology Department, College of Telecom \& Information, Technical \& Vocational Training Corporation, Riyadh 11564, Saudi Arabia; yobanikhalaf@tvtc.gov.sa

* Corresponding authors: wajdi.aljedaani@unt.edu (W.A.); mwmvse@rit.edu (M.W.M.)

Abstract: The COVID-19 pandemic brought about many challenges to course delivery methods, which have forced institutions to rapidly change and adopt innovative approaches to provide remote instruction as effectively as possible. Creating and preparing content that ensures the success of all students, including those who are deaf and hard-of-hearing has certainly been an all-around challenge. This study aims to investigate the e-learning experiences of deaf students, focusing on the college of the Technical and Vocational Training Corporation (TVTC) in the Kingdom of Saudi Arabia (KSA). Particularly, we study the challenges and concerns faced by deaf students during the sudden shift to online learning. We used a mixed-methods approach by conducting a survey as well as interviews to obtain the information we needed. Our study delivers several important findings. Our results report problems with internet access, inadequate support, inaccessibility of content from learning systems, among other issues. Considering our findings, we argue that institutions should consider a procedure to create more accessible technology that is adaptable during the pandemic to serve individuals with diverse needs.

Keywords: education; e-learning; deaf and hard of hearing; accessibility; Saudi Arabia; COVID-19

\section{Introduction}

The COVID-19 pandemic has necessitated the introduction of various public health measures to control its spread, including social distance measures. Such policies have affected nearly every sector of the economy, including education. Unfortunately, Gleason et al. [1] indicated that People With Disabilities (PWD) are often disproportionately affected in times of drastic and unintended changes. In the case of COVID-19, PWD are facing challenges in education because social distance measures have forced education institutions to shift from face-to-face learning to e-learning. As noted by Hanjarwati and Suprihatiningrum [2], some of the challenges faced include a lack of support, expensive internet access, the inability to work with the e-learning system, among others. It is important to raise awareness of how inclusivity in education can be achieved during the COVID-19 era, such as promoting the use of blended learning, providing sign language options, and improving support for disabled persons [3]. It is also important to resolve barriers to education for disabled students, which include technical problems, time, absence of simultaneous translation, among others [4]. 
In the last few years, studies on challenges associated with e-learning depended on the evolution as well the development of the e-learning system $[5,6]$. There are usually three types of interactions in e-learning systems, i.e., teacher to learner, learner to course contents, and learner to learner interaction [7]. Several studies have been conducted in Saudi Arabia to analyze the impact of COVID-19 on multiple factors, such as financial, psychological, political, and societal attitudes [8-11]. Furthermore, a number of studies investigated the use of online learning within Saudi Arabia during the COVID-19 period. For instance, research by Almekhlafy [12] focused on online learning of English courses using blackboard, and [13] examined the student satisfaction with the teaching quality of case-based discussion (CBD) sessions. Another study by Alshehri et al. [14] investigated the online learning facilitated syllabus delivery and assessments during COVID-19 and found that it was important to improve IT infrastructure, teacher training on online education, and student engagement, whereas [15] found that it was challenging to teach complex scientific concepts through online means, and there was low interaction between students.

However, studies performed in Saudi Arabia on disability, specifically with deaf students, are limited. There are only two studies that investigated deaf education during the pandemic. Madhesh [16] investigated the deaf students' situations through 20 ministry of education channels that were utilized during the locked down period. The goal of the study to provide an alternative educational method aimed for Deaf students. The second study was conducted by Alsadoon and Turkestani [4], where they investigated the obstacles that the instructors faced while they were teaching for online classes. Both studies were conducted on teachers of deaf students, but they did not examine the deaf students challenges and concerns during the sudden shift to online learning. Our study is the first to focus on challenges deaf students have faced, when transitioning to online learning during the pandemic. More specifically, this study is unique since, compared to other countries, online learning is not very established in Saudi Arabia, and its implementation has mostly been heightened by COVID-19. Saudi society is also traditional and conservative, wherein the deaf culture is still new and not well-established [17]. Thus, such students may have low self-esteem in communication [18], which may affect how they learn using the e-learning platforms. Furthermore, the context of this research is unique in terms of its gender focus, given that the Technical and Vocational Training Corporation (TVTC) only admits male students, unlike the participants in other studies that were both male and female. Therefore, the context of this study is very unique and its findings will be a great contribution to the body of research on the subject.

The aim of the current study is to explore the e-learning experiences of deaf students during the COVID-19 period, focusing on the Technical and Vocational Training Corporation (TVTC) in the Kingdom of Saudi Arabia (KSA). To explore the e-Learning experiences of deaf students during the COVID-19 era at TVTC, a mixed-methods approach was used. First, we conducted an interview to collect preliminary insights. The interviews were performed on eight deaf students who voluntary involve in the study. Then, we perform a survey in order to obtain the views of deaf students whose education had been disrupted by the pandemic. The survey helped in discovering new insights and estimating the prevalence of some aspects using a larger population, as well as providing explanations for support or opposition to some questions. Since the education of deaf students via online learning have not been previously investigated, this study will shed light on issues and challenges that can occur for the deaf students while learning online. In this study, we investigate the following research question:

$\mathrm{RQ}_{1}$ : What are the challenges and concerns that deaf and hard-of-hearing students are having with an online education during COVID-19 pandemic?

This RQ will guide this research by investigating the difficulties, challenges, and concerns of deaf students in the pandemic period. We will answer this question by exploring the students' perspectives of TVTC college by interviews and survey investigating of the learning processes during COVID-19. 
The contributions of this paper are:

- $\quad$ To explore the challenges faced by deaf students during the pandemic.

- To identify how issues faced by deaf students during the COVID-19 pandemic can be solved.

The rest of this paper is organized as follows: Section 2 presents background information on our case study (TVTC). Section 3 discusses related work. Section 4 provides an overview of the materials and methods used in this study to investigate the challenges of deaf and hard-of-hearing students of TVTC during the COVID-19 pandemic. Section 5 explains our research findings, and Section 6 discusses our results. Finally, Section 7 highlights the limitations of our research, and future work directions. Section 8 summarizes our conclusions.

\section{Background}

This section provides information on the TVTC training institution. It also discusses deaf education in the TVTC.

\subsection{Case Study Selected}

The Technical and Vocational Training Corporation (TVTC) is a public tertiary education institution in the Kingdom of Saudi Arabia, which was established in 1980. TVTC provides vocational education and training, making it important in workforce development. It consists of three sectors: vocational training centers, technical colleges, and secondary institutions, whose numbers are 65, 35, and 35, respectively. The TVTC has also provided accreditation to approximately 1000 private institutions. Thus, the TVTC is very instrumental in KSA's tertiary education and greatly contributes in providing labor supply to national and international labor markets [19].

\subsection{Deaf Education in TVTC}

There are four branches that deaf students can go to in TVTC, where they can access special education programs. The branches are distributed in the KSA, particularly in the middle and central areas. The numbers of such institutions, with their locations, are as follows: (1) Riyadh, (2) Madinah, (3) Buraydah, and (4) Dammam. All these branches teach two majors: business and computer technology. The number of the students are almost less than 100 at each campus. However, the deaf students in the institutions are not studying with other students without disabilities. According to Özokcu and Yildirim [20], disabled students are afraid to learn in inclusive classes because they are treated differently from others. In terms of teachers, the majority of the teachers are specialized (for specials educations), except for the general courses, such as English, Mathematics, or such other classes. Currently, most teachers are working without interpreters because they are conversant with sign language. For those teachers that are not familiar with sign language, they seek the assistance of interpreters. Currently, there are only three interpreters in the department because there are only a few students. If deaf students need assistance in any of the college services, they contact the department to provide them with an interpreter. Mostly, if students are holding seminars with spoken lecturers, they have to request for an interpreter before the session.

\subsection{Pre-Pandemic Learning Process}

The normal education process in Saudi Arabia involves face-to-face learning, which entails training in the classroom that has been conducted since the 1950s [21]. The face-to-face learning includes in-person lectures and text-book readings, which were mostly preferred in the pre-pandemic period because they emphasize on human-human interactions [22] With the advent of technology, blended learning was introduced in Saudi Arabia, where face-to-face interactions were complemented with technology. For example, as of 2016, TVTC had introduced a Learning System Management (LMS) known as Doroob to make 
learning more interactive and student-centered [23]. The learning process at TVTC in the pre-pandemic period was as follows:

- Students did not have experiences on how to use the full functionality of Blackboard, except to review course materials [24].

- Students used to give their homework and projects as hand-outs or using Dropbox to submit them. For project courses, student used to email teachers about any updates and the final submission of the course delivery.

- Students used Rayat (a portal enables students/trainees to obtain many services such as the tracking training record and the attendance and grades, etc.) [25] to access their grades, personal information, and their process of attending their courses.

\subsection{Learning Management Systems (LMSs)}

Learning Management Systems (LMSs) have become very popular in modern universities because of their ability to deliver content remotely, enhance interactions, improve feedback, and provide analytics to teachers to assess performance [26-28]. The first LMS system was known as FirstClass and was developed in 1990 [26]. Some of the most popular LMS applications in Saudi Arabia today are: Blackboard (89\% popularity), Moodle (7\% popularity), and D2L (4\% popularity) [26]. Therefore, Blackboard is the most popular LMS application in institutions of higher learning in Saudi Arabia.

In 2016, TVTC had introduced an LMS system known as Doroob to make learning more interactive and student-centered [23]. Before COVID-19, Saudi institutions, such as TVTC and King Saud University, were gradually adopting Blackboard LMS in order to improve their online learning channels [28]. However, the disruption of learning brought by COVID-19 in Saudi Arabia led to a sudden and quick shift towards Blackboard LMS [12].

\section{Related Work}

This section provides the related work to our study. We examine studies that studied the education of deaf and hard-of-hearing students and accessibility with deaf students. Then, we demonstrate how our work is different from the previous studies. We split the related work into two parts: (1) studies exclusively focused on deaf students during COVID-19 and (2) studies focused on accessibility with deaf students. Table 1 presents a summary of systematic analysis studies investigated on deaf and hard of hearing students during the COVID-19 pandemic.

\subsection{Deaf Students during COVID-19 Studies}

Several studies have addressed the subject of deaf and hard of hearing (DHH) studies. For instance, Kritzer and Smith [29] conducted a survey in the United States, which emphasized the need for parents to seek appropriate learning services and opportunities for their DHH children and communicate with them. Another study by Smith and Colton [30] utilized a literature review method and proposed using YouTube channels in teaching DHH students during the COVID-19 pandemic. The authors demonstrated how YouTube videos were made and shared and their usefulness in educating DHH students. Further, Sutton [31] utilized a literature review methodology and evaluated the best practices to help DHH students during COVID-19, such as providing speech-to-text services and facilitating communication through accommodation. Research by Lazzari and Baroni [32] investigated remote teaching experiences in Italy and found that remote teaching using technology helped learning during COVID-19, although some challenges were experienced, such as inadequate materials. Another study by Alsadoon and Turkestani [4] sought to identify the obstacles to e-learning and found that technical problems, time, and translation problems were severe challenges to DHH distance learning.

Research by Fernandes et al. [33] in Indonesia investigated how deaf voters were educated and indicated that videos effectively conducted voter education in Indonesia and visual and social media. Furthermore, in their study, Lynn et al. [34] evaluated how students were learning chemistry during the pandemic and found that access services, 
such as interpreters and captioners, were vital to DHH education, and making sufficient accommodations ensure inclusion. Another piece of research by Swanwick et al. [35] was conducted in Ghana to determine how the pandemic had affected deaf education and found that exclusion for DHH students was different in various cultural contexts and developmental areas. Research by Paatsch and Toe [36] utilized a literature review methodology and indicated that DHH students in typical classrooms developed pragmatic skills and proposed using the conversation model to deal with the challenges faced by such students. Finally, Tomasuolo et al. [37] conducted exploratory research in Italy and found that initiatives at the political and informal level promoted sign language and assisted in DHH education during the pandemic.

\subsection{E-Learning System for Deaf Students}

Previous studies have suggested the importance of introducing e-learning systems for deaf students. For example, a study by Alcazar et al. [38] found that introducing a speech-to-visual approach e-learning system had a great advantage when teaching deaf students because it enabled their comprehension of material and addressed their individual needs. Furthermore, a study by Batanero et al. [39] found that adopting an improved Moodle learning platform improved the academic performance of deaf and deaf-blind students by $46.25 \%$ and $87.5 \%$, respectively. In addition, Batanero-Ochaita et al. [40] found that deaf students had a positive attitude towards the Moodle Learning Platform, although their perception differed on the ease-of-use and difficulty when using the platform.

\subsection{Deaf Students in Online Learning}

Several studies have looked at the subject of online learning for deaf students. For example, a study by Long et al. [41] focused on blended learning for deaf and hard-ofhearing students and found that the inclusion of online learning aspects improved their interactions with their teachers and other students. Another study by Slike et al. [42] found that, although there are many successes in teaching deaf students using online means, there are also challenges related to system 'glitches', lack of captions, teachers who are not used to handling deaf students in virtual classrooms, among others. In addition, a study by Yoon and Kim [43] suggested the need to improve learning materials in the classroom because it established that captions have a significant effect on the content comprehension of deaf students taking online courses.

A study by Burgstahler [44] was conducted to identify the online learning practices that are most suitable for students with disabilities and found the "Universal Design" (UD) strategy to be very effective in inclusive educational practices. Research by McKeown [45] found three types of challenges that faced deaf students when accessing online learning: course content and material challenges, learning management system (LMS) challenges, and course content and material challenges. A study by Carpenter et al. [46] established that online technology had improved deaf education and made communication easier and proposes the use of best practices that can boost the utilization of online learning. Another research by Mohammed [47] found that deaf students participating in online education faced problems related to institutional support, social inequalities, and inappropriate sociolinguistic history. Another study by Musyoka and Smith [48] found that, since online deaf learning involves the use of English and American Sign Language (ASL), language barriers were considered a challenge. A study by Long et al. [49] reported that online learning for deaf students provides special benefits that were realized through academic achievement and the quality of interaction in online learning platforms greatly determined the success of the students. Additionally, a study by Caupayan and Pogoy [50] established that, although deaf students faced challenges in online learning, the support they received from various stakeholders helped them to overcome them. From the related work, there is no study addressing online learning for deaf students in Saudi Arabia, which is the focus of the current study. 
Table 1. Summary of systematic analysis studies for deaf and hard of hearing students in chronological order.

\begin{tabular}{|c|c|c|c|c|c|c|c|}
\hline Study & Year & Purpose & Method & Source of Info & Participants & Sample Size & Study Location \\
\hline Long et al. [41] & 2007 & $\begin{array}{l}\text { Understanding student perceptions of communication in } \\
\text { blended learning courses }\end{array}$ & Survey & NTID & Students & 908 & United States \\
\hline Slike et al. [42] & 2008 & $\begin{array}{l}\text { Investigating successes and challenges in offering } \\
\text { online courses in a "virtual classroom" format to deaf } \\
\text { hard of hearing }\end{array}$ & $\begin{array}{l}\text { Online Synchronous } \\
\text { Tool }\end{array}$ & $\begin{array}{l}\text { University of } \\
\text { Pennsylvania }\end{array}$ & Students & 26 & United States \\
\hline Yoon and Kim [43] & 2011 & $\begin{array}{l}\text { Capturing the effects of captions on deaf students' content } \\
\text { comprehension, cognitive load, and motivation in online learning }\end{array}$ & $\begin{array}{l}\text { Comprehension test } \\
\text { \& survey }\end{array}$ & $\begin{array}{l}\text { Korean Nazarene } \\
\text { University }\end{array}$ & Students & 62 & Korean \\
\hline Burgstahler [44] & 2015 & $\begin{array}{l}\text { Identifying online learning practices make social inclusion } \\
\text { possible for individuals with disabilities }\end{array}$ & Literature review & N/A & N/A & $\mathrm{N} / \mathrm{A}$ & N/A \\
\hline Alcazar et al. [38] & 2016 & $\begin{array}{l}\text { Creating a supplementary English elearning system made } \\
\text { for the Deaf }\end{array}$ & Survey & $\begin{array}{l}\text { Philippine Institute } \\
\text { of the Deaf }\end{array}$ & $\begin{array}{l}\text { Students, } \\
\text { Teachers }\end{array}$ & $\mathrm{N} / \mathrm{A}$ & Philippines \\
\hline McKeown [45] & 2019 & $\begin{array}{l}\text { Proposing a model which describes the three barriers deaf } \\
\text { students might encounter in an online learning situation }\end{array}$ & Literature review & N/A & N/A & $\mathrm{N} / \mathrm{A}$ & $\mathrm{N} / \mathrm{A}$ \\
\hline Batanero et al. [39] & 2019 & $\begin{array}{l}\text { Testing a redesign of the Moodle platform on deaf and } \\
\text { deaf-blind students }\end{array}$ & Empirical study & Moodle platform & Students & 23 & $\mathrm{~N} / \mathrm{A}$ \\
\hline Counselman et al. [46] & 2020 & $\begin{array}{l}\text { Exploring current trends in online higher education, data on } \\
\text { the experience of Deaf/deaf/Hard of Hearing students and } \\
\text { current options for improving inclusively in the online classroom }\end{array}$ & Literature review & $\mathrm{N} / \mathrm{A}$ & N/A & $\mathrm{N} / \mathrm{A}$ & $\mathrm{N} / \mathrm{A}$ \\
\hline Fernandes et al. [33] & 2020 & Examining how the education of voters for deaf people & Interview & GERKATIN & Students & 33 & Indonesia \\
\hline Lynn et al. [34] & 2020 & Identifying Successes and challenges in teaching chemistry & Author's insights & NTID & N/A & N/A & United States \\
\hline Tomasuolo et al. [37] & 2020 & Exploring the impacts of the recent pandemic crisis & Exploratory research & Literature review & N/A & N/A & Italy \\
\hline Kritzer and Smith [29] & 2020 & Recommending parents about educating DHH children & Survey & United States & Parents & 133 & United States \\
\hline Swanwick et al. [35] & 2020 & $\begin{array}{l}\text { Investigating the impact on deaf adults, children and their } \\
\text { families, focusing on issues of inclusion }\end{array}$ & Interview & Ghana & $\begin{array}{l}\text { Teachers, } \\
\text { leaders, } \\
\text { Students }\end{array}$ & 6 & Ghana \\
\hline Lazzari and Baroni [32] & 2020 & Presenting the remote teaching experience & Survey & Scuola Audiofonetica & Students & 233 & Italy \\
\hline Paatsch and Toe [36] & 2020 & Investigating pragmatic skills among deaf children & Literature review & Existing evidence & N/A & N/A & Australia \\
\hline Krishnan et al. [51] & 2020 & Identify the Challenges Faced by hearing impairment & Survey & MySkill Foundation & Students & 10 & Malaysia \\
\hline Halley Sutton [31] & 2020 & Suggesting best practices if courses shift to online learning & Literature review & Existing evidence & $\mathrm{N} / \mathrm{A}$ & $\mathrm{N} / \mathrm{A}$ & United States \\
\hline Kylie Sommer [52] & 2020 & Identify the Effect on deaf and hard of hearing & Survey & Lee University & Students & 36 & United States \\
\hline
\end{tabular}


Table 1. Cont.

\begin{tabular}{|c|c|c|c|c|c|c|c|}
\hline Study & Year & Purpose & Method & Source of Info & Participants & Sample Size & Study Location \\
\hline Mantzikos and Lappa [53] & 2020 & Analyzing the difficulties and barriers individuals deaf & Literature review & Existing evidence & $\mathrm{N} / \mathrm{A}$ & $\mathrm{N} / \mathrm{A}$ & Greece \\
\hline \multirow[t]{2}{*}{ Mohammed [47] } & 2021 & Investigating how an emergent system of e-learning that started & Interview & Primary school & $\begin{array}{l}\text { Students, } \\
\text { teachers, }\end{array}$ & $\mathrm{N} / \mathrm{A}$ & Trinidad and \\
\hline & & $\begin{array}{l}\text { during crisis conditions affects the linguistic access of deaf } \\
\text { students }\end{array}$ & & \& secondary school & $\begin{array}{l}\text { interpreters, } \\
\text { parents }\end{array}$ & & Tobago \\
\hline Batanero-Ocha et al. [40] & 2021 & Analyzing the difficulties and barriers individuals deaf & Empirical study & Moodle platform & Students & 23 & $\mathrm{~N} / \mathrm{A}$ \\
\hline Musyoka and Smith [48] & 2021 & $\begin{array}{l}\text { Identifying language barriers and academic performance when } \\
\text { discussing mainstreamed } \mathrm{D} / \mathrm{HH} \text { students' online teaching }\end{array}$ & Literature review & Existing evidence & $\mathrm{N} / \mathrm{A}$ & $\mathrm{N} / \mathrm{A}$ & United States \\
\hline Long et al. [49] & 2021 & $\begin{array}{l}\text { Understanding the factors contributing to the academic } \\
\text { achievement } \\
\text { and the interaction of students in online learning }\end{array}$ & Survey & RIT & Students & 88 & United States \\
\hline Caupayan and Pogoy [50] & 2021 & $\begin{array}{l}\text { examining and interpreting the lived experiences of } 14 \\
\text { purposively } \\
\text { selected deaf students who chose online modality for their } \\
\text { education }\end{array}$ & Interview & La Salle University & Students & 14 & Philippines \\
\hline This work & 2021 & Investigating the challenging and concerns of deaf students & Interview \& Survey & TVTC & Students & 65 & Saudi Arabia \\
\hline
\end{tabular}




\subsection{Accessibility with Deaf Students Studies}

Several studies have addressed the topic of accessibility with deaf students. For example, a study by Sommer [52] in the US utilized a survey method to demonstrate how access to information by DHH students has been hampered by the COVID-19 pandemic, which has had emotional effects on them. Another study by Mantzikos and Lappa [53] reviewed existing evidence on overcoming difficulties and barriers to deaf education. It established the use of media, such as educational TV programs, helped improve access to information, although it was essential to improve new principles and approaches that helped DHH students. Research by Krishnan et al. [51] in Malaysia used a survey method to investigate students' challenges during COVID-19 and found that accessibility by DHH students was hindered by a lack of familiarity to online devices, hearing devices, emotional effects of the pandemic, and disruptions to their education.

The current study deviates from those reviewed because it focuses on accessibility by deaf students in Saudi Arabia. Specifically, it focuses on TVTC in Saudi Arabia, which no other study has addressed. TVTC has adequate and trained faculty with a lot of experience, who offer more support for the deaf. This research also differs from the rest in terms of the methodology and because this study is a larger-scale research article in terms of the sample compared to the previous ones.

\section{Materials and Methods}

This section presents the approach of our study, information about the participants engaged in the study, the data collection process, details about the procedures that were followed in interviews and survey, and analyzes the data to address our research question.

\subsection{Study Approach}

This research was carried out in several stages as follows. Firstly, the survey and interview guides were created based on the research questions and a preliminary review of literature on the subject. Secondly, the survey was administered, and interviews were conducted by the researcher. Thirdly, the survey was analyzed, and transcripts were coded. Finally, thematic analysis was used to create a theme map, which was followed by the analysis of results.

To explore the e-Learning experiences of deaf students during the COVID-19 era at TVTC, a mixed-methods approach was taken. The specific methodologies used were case study and survey [54]. We considered two approaches to be appropriate for this study because of several reasons. The first reason is that the case study methodology allows us to investigate a particular phenomenon in its natural environment [55], which also applies to deaf students in the TVTC. Given that the COVID-19 situation is of a worldwide nature, we deemed it fit to use a survey in order to obtain the views of deaf students whose education had been disrupted by the pandemic. The survey technique was conducted using two data collection methods, namely survey and interviews.

The nature of the current study is that it is both descriptive and exploratory qualitative. The descriptive aspect provided observations on how deaf students are e-learning in the current pandemic, while the exploratory qualitative aspect sought to identify their experiences in the COVID-19 era [56,57]. In this study, we followed the case study guidelines by Runeson and Höst [57] and survey guidelines by Kitchenham and Pfleeger [58]. To analyze qualitative data, we combined our methods with a deductive thematic analysis [59-61]. The thematic analysis was selected for this research [61]. The reason for selecting thematic analysis was to enable the researcher to identify themes in the study that could help interpreting interviews and derive meanings. Various prior studies conducted on deaf and hard of hearing have found this method to be adequate [62,63].

One of the advantages of thematic analysis is flexibility, and it was selected in this study because it can follow a given theoretical framework, unlike grounded theory [64]. The theoretical framework [61] employed in this research is deaf and hard of hearing challenging (described in detail in Section 5) stages, meaning that the thematic analysis 
approach used will be deductive. The researchers assumed a connection between the respondents' replies and the meanings. Hence, the essentialist/realist thematic analysis approach was adopted [65]. The directions given by Braun and Clarke [61] guided the thematic analysis technique in this paper.

\subsection{Data Collection}

This study's data were collected in two steps. First, we conducted interviews to collect preliminary insights, similar to the empirical approach of collecting evidence by surveys. The interview responses' patterns gave crucial insights on e-learning experiences for deaf students. Secondly, from the findings of the interviews, we designed a survey and distributed it to the deaf students. The reason for using the survey was to corroborate the data from the interviews with a higher sample size. We conducted a survey of deaf students in the TVTC. By conducting the survey, an in-depth investigation of the research question could be explored comprehensively and systematically.

\subsection{Interviews}

The researcher conducted interviews to explore the general experiences of deaf students learning at the TVTC during the pandemic. The following sections provide the interview protocol, participants, and analysis of the interview data.

\subsubsection{Protocol}

To ensure that researchers received both structured and unstructured responses, a semi-structured format was used in creating the interview schedules. The interviewer used the funnel method so that the interviews would look like conversations [66], as opposed to a question-and-answer format. Such an approach encouraged the interviewees to speak their minds freely, although the researcher ensured that the topics of interest in the discussion were addressed. The mentioned approach allowed the researcher to meet the exploratory and observational objectives of the study. To ensure validity of the interviews, investigator triangulation was conducted [67], where the questions were thoroughly discussed, and interviews were conducted by three researchers. It was generally agreed that the questions were sufficient in collecting information about the experiences of deaf students during the COVID-19 pandemic.

The interview consisted of 25 questions that asked various aspects that were in line with the objectives of this study. Given that a semi-structured approach was used, the interview questions acted as a guide for the researcher. The questions were used as conversation starters, after which the conversations flowed without disruptions. Table 2 presents the set of interviews questions. Interviews were conducted by the researcher via the Zoom platform using the Arabic language. All the respondents were native Arabic speakers; hence, the choice for the interviewing language was made. Given that Arabic is the first language in Saudi Arabia, it enabled the researcher to easily interact with the interviewees and obtain more insight from them. It is crucial to mention that the students were speaking sign language, and an interpreter translated the signed language to the Arabic spoken language. We considered this accommodation vital for the smooth running of the interviews, and since none of the researchers was conversant with sign language, we hired an interpreter.

\subsubsection{Participants}

The voluntary response sampling method explained by Murairwa [68] was used because the researcher wanted to include only those deaf students that were willing to share their experiences. Therefore, out of all the participants that were willing to take part in the research, only those who volunteered were interviewed. The interview stage was exploratory, and therefore, the researcher was not concerned about non-generalizability of results because of using the voluntary response sampling method. 
The number of interviewees that agreed to take part were 8 , out of a population of 80 deaf students that had been contacted. The interviewed students were all male because the college admits male students only. The individuals were contacted via the students' emails, and their responses towards the participation request were noted down. All of the 8 students were male, 4 in each of the 2 majors at TVTC (computer technology and business). Table 3 presents the demographic summary of the participants. The equal splitting between the two majors was conducted in order to have a good overview of each category. The interview duration was between 20 and $30 \mathrm{~min}$. We compensated all participants with a $\$ 25$ prepaid gift card.

Table 2. The set of interviews questions.

\begin{tabular}{|c|c|}
\hline First Background and Demographics & Fourth Challenges and Concerns \\
\hline Years of age, and study major & What were your distractions while you were learning online? \\
\hline Do you have access to a device for learning online? & What were your most challenges during online learning? \\
\hline What device did you use for online learning? & How was your learning environment at home? \\
\hline Second Generic Views & How did you communicate with your teachers? \\
\hline How would you describe your experience in learning online? & Were you able to access the class materials via Blackboard? \\
\hline What type of device did you use for online learning? & $\begin{array}{l}\text { How you ever encounter any barriers or issues communicating with } \\
\text { your teachers or department? }\end{array}$ \\
\hline How did you study for & Did all videos have subtitles? \\
\hline Based on your experience in online learning, what do you prefer now? & Do you have a printed text transcript of audio content on the website? \\
\hline Third E-learning Tool & Fifth Students recommendations \\
\hline What is your perspective on Blackboard platforms? & $\begin{array}{l}\text { What do you feel are the benefits of online courses, such as those } \\
\text { provided during COVID-19? }\end{array}$ \\
\hline $\begin{array}{l}\text { Did you use any other e-learning tools? Why? } \\
\text { Did you train on Blackboard? if not, did teachers and department } \\
\text { shared with you resources? }\end{array}$ & What are the things that you would like to change in online learning? \\
\hline
\end{tabular}

Table 3. Demographics information. Each participant (P\#) answered the interview questions.

\begin{tabular}{ccccccc}
\hline Participant & Age & Major & Year & Derive Used & $\begin{array}{c}\text { Received Support } \\
\text { Yes/No }\end{array}$ & $\begin{array}{c}\text { Prefer Learning Online } \\
\text { Yes/No }\end{array}$ \\
\hline P1 & 23 & $\begin{array}{c}\text { Computer } \\
\text { Technology }\end{array}$ & 3 & Laptop & Yes & No \\
\hline P2 & 22 & $\begin{array}{c}\text { Computer } \\
\text { Technology }\end{array}$ & 2 & Laptop & No & No \\
\hline P3 & 22 & Business & 2 & Laptop & No & No \\
\hline P4 & 21 & Business & 4 & Mobile Phone & No & Yes \\
\hline P5 & 24 & Business & 1 & Mobile Phone & Yes & No \\
\hline P6 & 20 & $\begin{array}{c}\text { Computer } \\
\text { Technology }\end{array}$ & 3 & Computer & No & Yes \\
\hline P7 & 22 & Business & 3 & Mobile Phone & No & No \\
\hline Computer & 4 & Computer & Technology & 23 & &
\end{tabular}

\subsubsection{Data Analysis}

The interviews were transcribed, which prepared them for the data analysis stage that was conducted through thematic analysis. The first stage of the thematic analysis method is reading the scripts in detail to facilitate coding the interviews in line with the research questions. In this study, codes were used to categorize the responses of the participants according to the selected topics. Subsequently, the codes were utilized in creating a theme map, which would illustrate the results of the study.

\subsubsection{Transcript Coding}

The interview responses given in the interviews were scanned in order to facilitate the coding process. The researcher assigned codes according to topics that expressed certain opinions, attitudes, and experiences that related to the research question. Given that the interviews were long, the researcher identified only the relevant responses to the current study. In the initial step, the researcher scrutinized the interview scripts and created a list of codes that emerged from the responses. The second step involved evaluating and investigating the codes to ensure that they were representative of the research questions. In 
the third step, the researcher revised the codes, which involved merging or dividing some of them.

\subsubsection{Deducing Themes}

The researcher categorized the generated codes into various themes. In this research, a theme is considered a pattern of responses that relate to a given research question. Thematic analysis involves constant revision of themes as the researcher investigates the interview text, which ultimately leads to the creation of a theme map [61]. In this study, a theme map demonstrated the insights derived from the interviews and their relationships. Such an approach ensured that detailed and in-depth descriptions of the research subject was conducted without interference from irrelevant data. Theme mapping was conducted and revised three times by the researcher. An illustration of the research findings of the theme map is given in Figure 1.

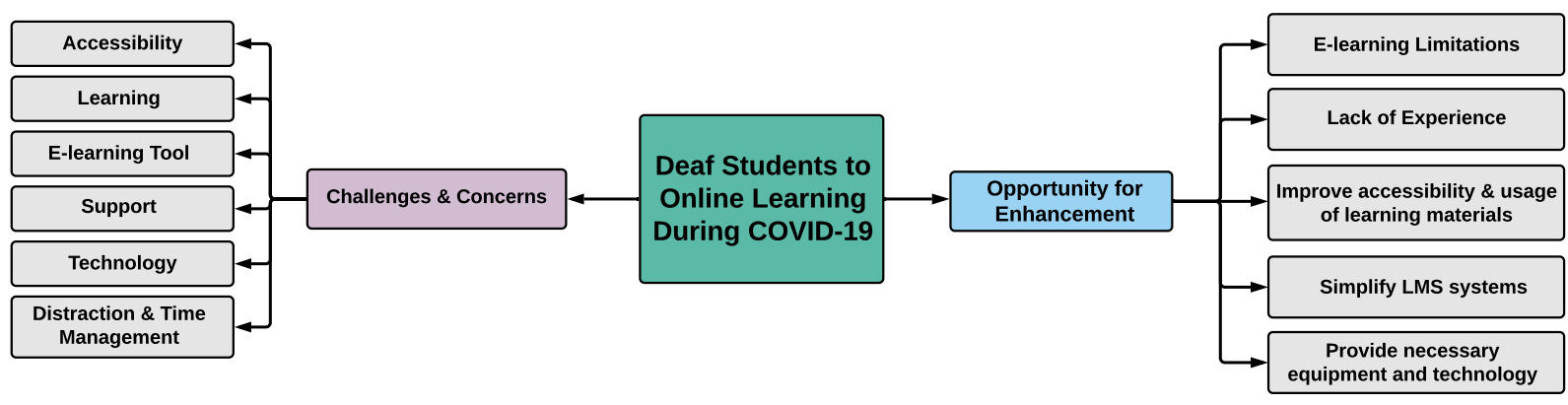

Figure 1. Thematic analysis findings in the form of a theme map.

\subsection{Survey}

After identifying the relevant topics from the interviews and considering the research questions, the survey was designed. The survey was created to corroborate the interview findings, discover new insights, and estimate the prevalence of some aspects using a larger population.

\subsubsection{Design}

The designing of the survey began with generating 100 questions and statements that were developed by the author. The survey was divided into four sections according to the themes that had been generated in the interviews section. Time was taken to revise the questions in order to remove those that were considered ambiguous, irrelevant, repeated, or of a personal nature. The revision of the questions paved the way for reducing the questions from 100 to 72 . To evaluate the survey's effectiveness and overall experience, a pilot study was conducted with five deaf students. The feedback was that the survey was very long, some of the questions were repeated, and that it was important to arrange the questions in a logical manner.

Based on that information, we reduced the number of questions from 72 to 42 and grouped them into 3 sections. Easier questions were given first to encourage the respondents to answer the questions. Demographic questions were also placed at the end of the paper so that they do not lead to no-response if placed at the beginning. The researcher included both closed-ended and open-ended questions in order to provide a chance for the respondents to give their personal insights without restrictions. For our final survey, we included 42 questions that can be broken down as follows: 18 Likert questions, 19 multi-choice questions, and 5 that were open-ended. The Likert questions used a 5-point scale that indicated the extent of interest, concurrence, or importance of an aspect. It was also deemed appropriate to make some of the questions optional so that the respondents do not feel pressure to answer them just for the sake of completing the survey. The survey were designed using Google Forms, which also helped in collecting the data. It is also important 
to state that the survey was created in the Arabic language, which is the first language in Saudi Arabia, to enable the respondents to understand the questions easily [69]. The survey and interviews were carefully translated into English by three authors. Subsequently, a three-stage process was conducted to check the translated responses for their correctness. In the three-stage process, each of the three authors reviewed the translations and certified that they were accurate. Our survey questions are available in both Arabic and English in [70].

\subsubsection{Participants}

The survey link was shared through the students' emails. Out of the initial targeted number of 80 respondents, the researcher received 65 responses (response rate $=81.25 \%$ ), which is considered high [71]. All the respondents were male because the college has only male students. From the total number of participants, 26.2\% majored in computer technology, while $73.8 \%$ majored in business. The respondents were in their first, second, and third years of study.

\subsubsection{Data Analysis}

The results of the survey were analyzed by first merging some of the responses. For instance, strongly agree and agree were combined to give the general agreement rate. A weighted average response was developed to simplify the recording and analysis of the responses. For example, the disagreement percentage was the proportion of the responses that strongly disagreed or disagreed with a certain question. Analysis of quantitative data was conducted using $\mathrm{R}$ Language, which is a statistical computing package.

To facilitate the understanding of the quantitative data, it was corroborated with qualitative data. Such an approach helped in providing explanations for support or opposition to some questions. Several quotes were also provided, which were retrieved by reviewing the themes and codes that had been generated in the thematic analysis stage.

\subsubsection{Privacy and Data Protection}

We considered several privacy and data protection aspects. For instance, we anonymized all responses in order to hide the identity of the respondents that participated in the study. Furthermore, all the research materials, including responses received from participants, were secured in the researcher's laptop using passwords. Prior to participation, we requested consent from all potential respondents, who allowed us to use their information for the research.

\subsubsection{Rationale behind the Interview and Survey Questions}

We grouped our questions into five sections, as follows: background and demographics, generic views, e-learning tools, challenges and concerns, and students' recommendations. We created the questions based on the insights that had been gained from the related studies on the perspectives of deaf students in various other places. The rationale of creating and framing the questions the way we did was to obtain a broad picture of the challenges of online students within our research context.

\section{Study Results}

This section presents the findings of our study.

$\mathrm{RQ}_{1}$ : What are the challenges and concerns that deaf and hard-of-hearing students are having with an online education during COVID-19 pandemic?

A survey and interviews were conducted in order to obtain both quantitative and qualitative data. We have grouped our findings into seven challenges that will be discussed in this section.

As shown in Figure 2, we report the main challenges faced by deaf and hard-of-hearing students with an online learning education. The majority of the students (62 respondents 
$(96.9 \%))$ communicated that they were having network issues or unreliable internet access at home. Forty-two students $(75.4 \%)$ revealed that they have no access to tools to help facilitating the study and the many type distractions at home, such as the distraction of smartphones and televisions in the same room. A moderate subset of 34 students $(52.3 \%)$ were concerned about the difficulty of communicating with the instructors and the interactions were not feasible, whereas two students $(3.1 \%)$ were concerned about the collaboration with their fellow students. Twenty-five students (38.5\%) found that COVID19 makes fast internet connections more critical. Twelve students (18.5\%) mentioned that the development of the COVID-19 pandemic has resulted in life-altering employment shifts across Saudi Arabia. Five students (7.7\%) found that maintaining an unstructured work schedule can be difficult and hard to adjust to, whereas one of the students $(1.5 \%)$ found that the challenge is centered around the lack of interactions and feelings of isolation.

In the rest of this subsection, we provide more in-depth analysis of these challenges.

Select the top three most significant challenges you face while learning from home?

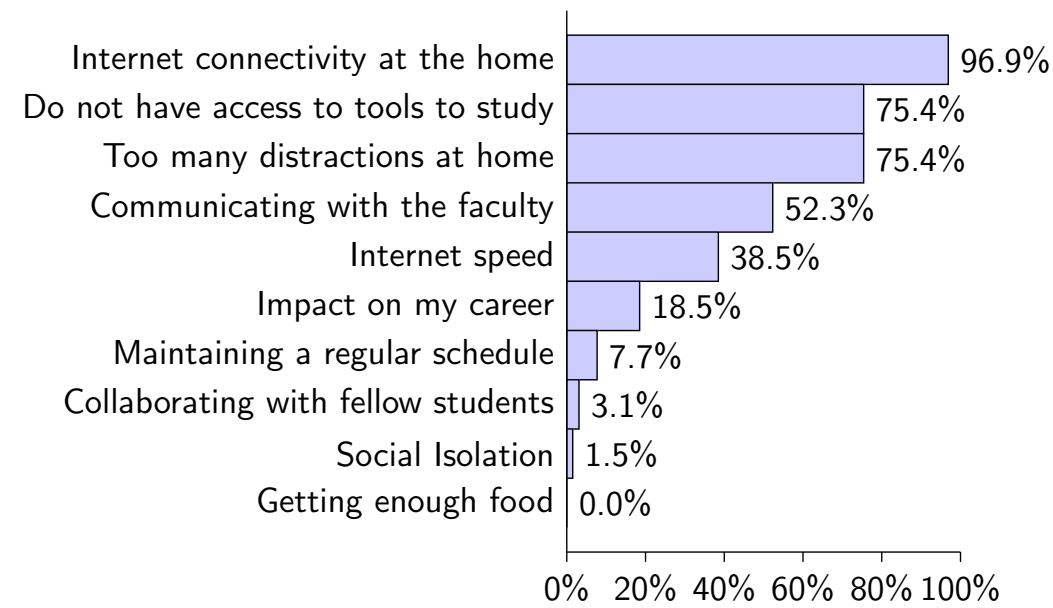

Figure 2. Presents the most challenges deaf students faced.

\section{(1) Issues associated with accessibility:}

In this section, we wanted to know whether students were accessing all the information on Blackboard, and our results are given in Figure 3. It was apparent that 47 students (72\%) faced challenges in accessing information on the platform. P8 noted that:

"at first, using Blackboard was extremely difficult and causing problems for getting course material and navigating the platform. Furthermore, there were different opinions because the department encourages us to use Blackboard, whereas the teachers encourage us to use different sites, so sharing class materials were very hard between the teacher and students. We ended up using social media application 'WhatsApp' to share the class materials."

a) Are you able to access all the contents of your classes on Blackboard at any time?

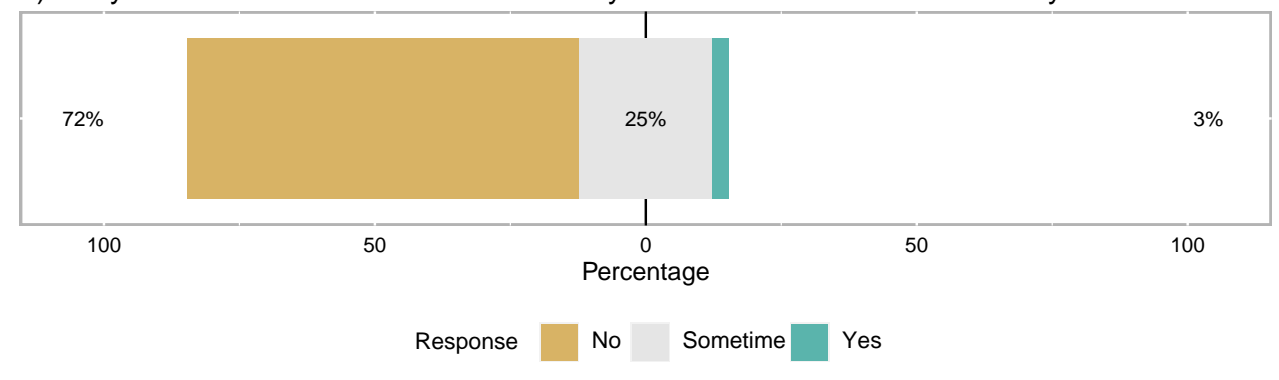

Figure 3. Accessibility of coursework materials. 
We also wanted to know whether the coursework materials were accessible, and our results are given in Figure 4. We determined that most of the students indicated that the materials were not easily accessible. P5 explained that:

"Blackboard was not friendly interface. I had an issue locating the exam component since there are a lot of headers and sub-headers in the navigation bar, and the font was very small hard to read."

b) The materials that have been given as part of my coursework are accessible to me (for example, captions, clearly described).

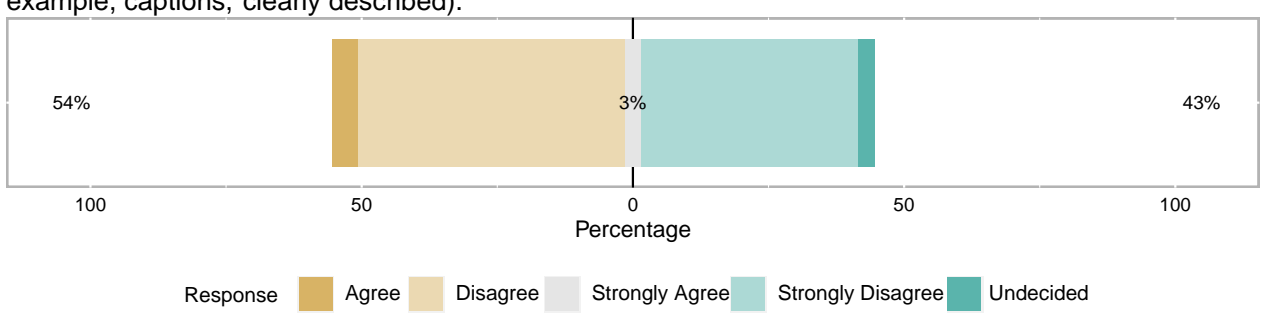

Responses: 65

Figure 4. Accessibility of materials on Blackboard.

We also asked students whether the blackboard pages were easy to navigate, whether the videos had subtitles, whether they had enough time to complete the assignments, and whether the text sizes were easily seen. Our results are given in Figure 5, where a majority of the students indicated a lack of accessibility in all four aspects mentioned. P3 explained that:

"Blackboard was in English interface, and it was hard for me to switch it to the Arabic language without any assistance. I missed many classes for this reason, and teachers were not recording the classes."

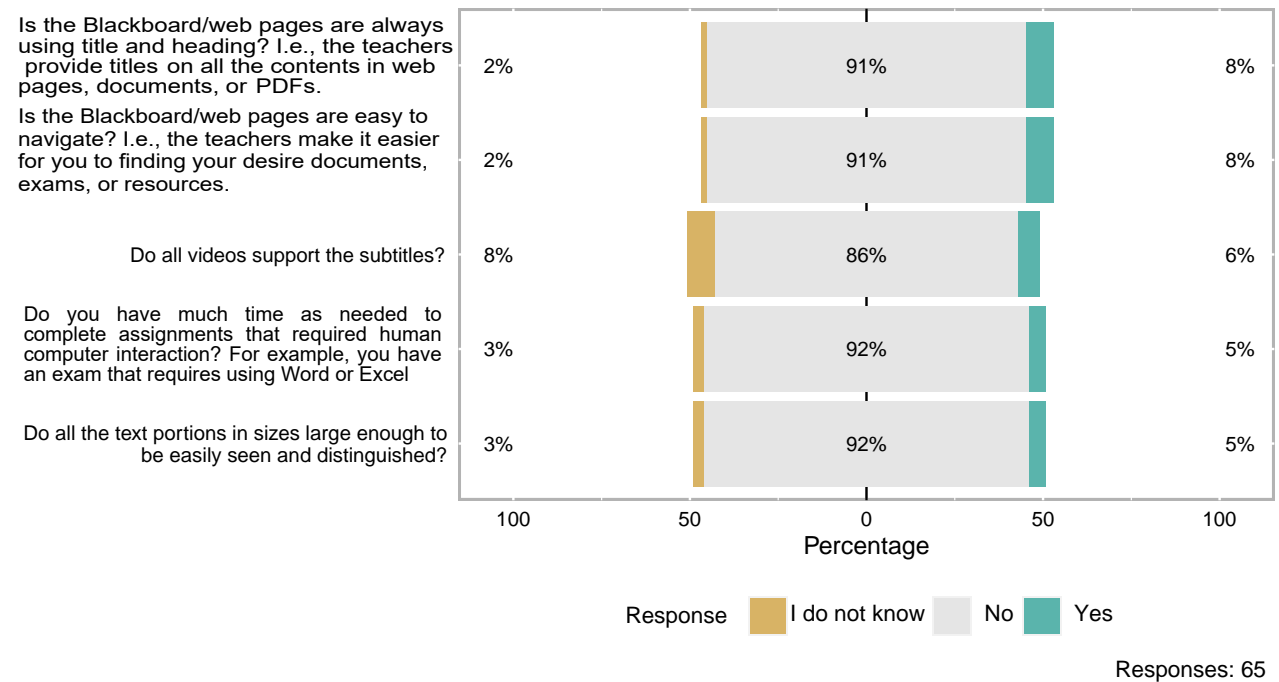

Figure 5. Responses to questions regarding to accessibility aspect.

\section{(2) Learning problems:}

In this sub-section, we wanted to identify the kind of learning challenges that the students faced during the pandemic. One of the questions we asked the respondents was whether the online learning was stressful during the pandemic, where 54 students (83\%) noted that it was extremely stressful. The results are given in Figure 6. 
d) How stressful is online learning for you during the COVID-19 pandemic?

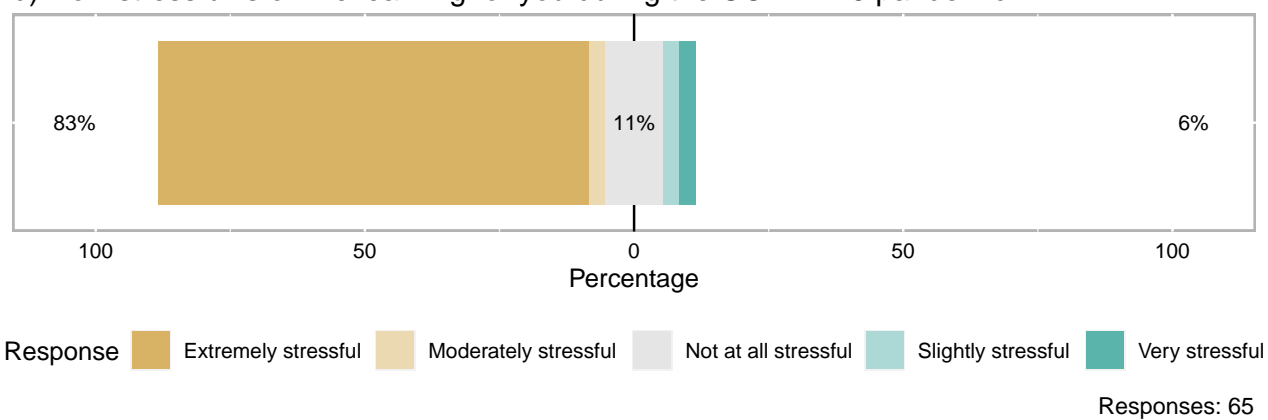

Figure 6. Stress in online learning during COVID-19 pandemic.

We also wanted to know whether online learning has been effective during COVID-19, and our results are presented in Figure 7. It was unfortunate that $40(62 \%)$ of the respondents indicated that their learning was not effective at all during the pandemic.

e) How effective has online learning been for you?

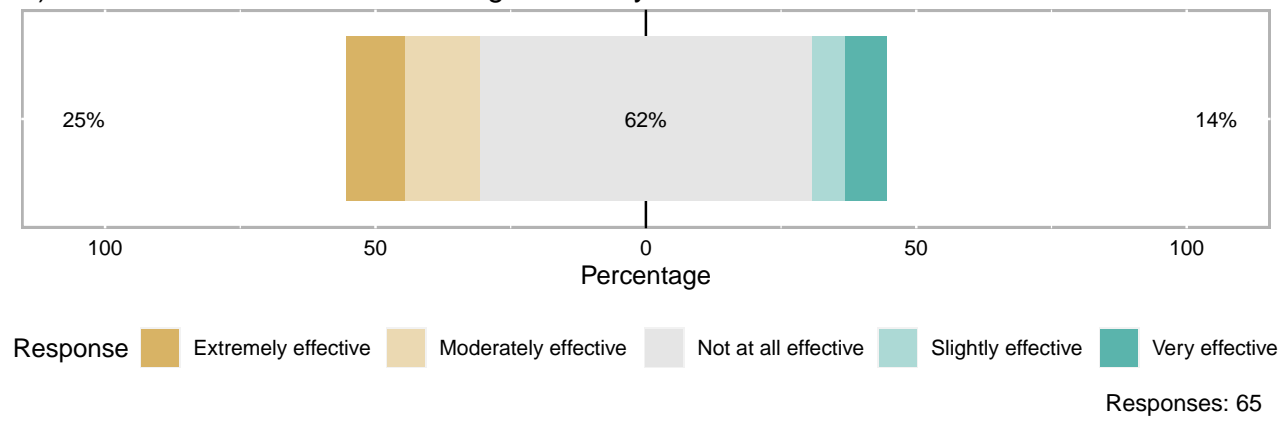

Figure 7. Effectiveness of online learning during the COVID-19 pandemic.

We also wanted to know how the educational performance of deaf students had been affected during COVID-19, and our results are given in Figure 8. Approximately 60 (92\%) of the respondents were very worried about their performance during the period. Such outcomes were caused by teaching and learning challenges in learning that deaf students have faced in the pandemic. P4 said that:

"Less than half of the materials were covered because the time was short, and we faced difficulties understanding the material. It has to be recorded for us to see it again, but there was nothing recorded."

Such situations affected the educational performance of students.

f) The impact of the coronavirus on your educational performance?

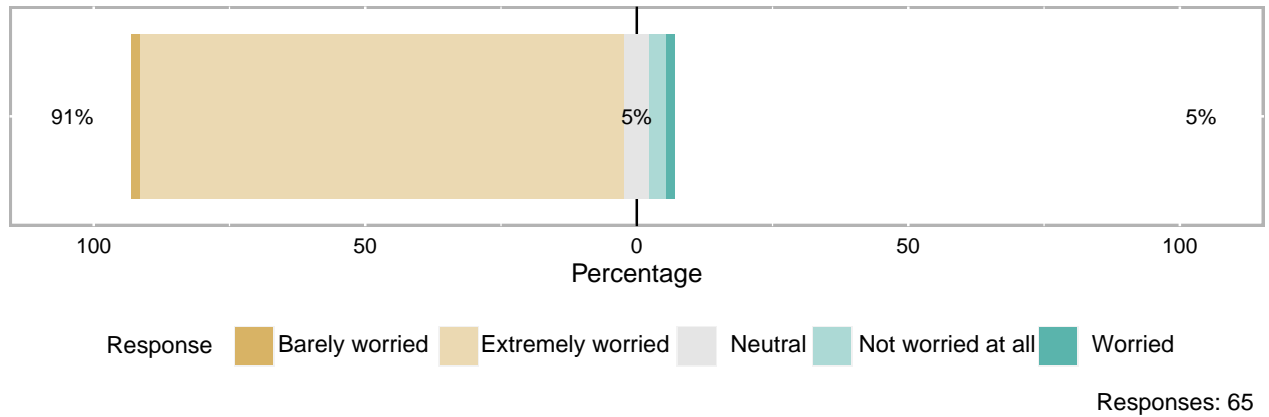

Figure 8. Impact of COVID-19 on educational performance. 


\section{(3) Challenges associated with e-learning tools:}

Using online e-learning as a tool for teaching is one of the challenges and factors influencing the acceptance and use of e-learning tools, and these tools have become a key part of pandemic life. The rate of participants agreement on the usage of Google Meet, Zoom, and Backboard was $49(75.4 \%), 13(20 \%)$, and $3(4.6 \%)$, respectively. From Figure 9, it is evident that Google Meet was the most preferred platform, followed by Zoom. A closer introspection reveals a shortcoming of Zoom and Blackboard over Google Meet that is the limitation of the visibility of the camera. We report samples of the participants' comments (P2) below to illustrate this challenge:

What is the most suitable e-learning platforms for you?

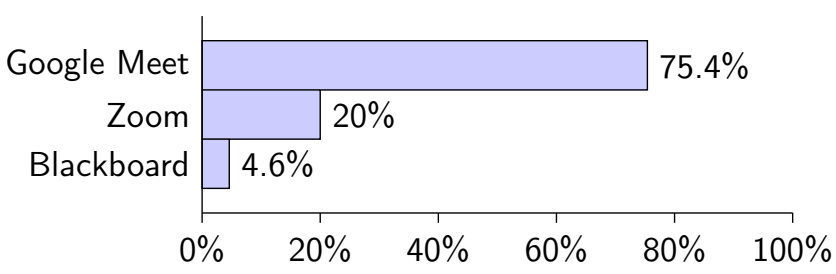

Figure 9. Presents the most suitable e-learning platforms students experienced.

"Zoom and google meet. Google meet was the best because all cameras were visible to us, whereas in Blackboard, we can only see four cameras."

\section{(4) Problems with communication:}

In this section, we wanted to know how helpful deaf teachers were to their students. Most of the students indicated that the teachers have not been helpful. Our results are presented in Figure 10. For those students that found their teachers not very helpful, they gave their reasons. For example, $\mathbf{P} 3$ said that:

"Communicate was my biggest issue, and there were difficulties in communicating with our teachers and the department. Some teachers take a while to respond, where others not responded at all."

Other challenges were related to the congruence of the technology used on both the students and teachers. P1 noted that:

"The teacher would call the student and sometimes presses on the name of the student or calls their name or waive at the student but in this case, the student cannot see, because the picture would be apparent only to the teacher but from the student view it was only visible for four students' camera, not all the class. So, the teacher would waive, but the student did not know because of the other four students, so it is always very late for the student to ask, and the teacher would answer: hold on, let me see which student needs me so I can show their camera."

Hence, the communication challenge greatly affected the helpfulness of the teacher towards the students. We also wanted to identify the communication means that students used to communicate with their teachers, and our results are in Figure 11. It was established that $60(93.8 \%)$ of the students used WhatsApp, while 13 (20.2\%) used Zoom. P5 said that:

"When the screen freezes, I take a picture and send it to the teachers via WhatsApp, and tell them I cannot log in." 
g) How helpful are your teachers while studying online?

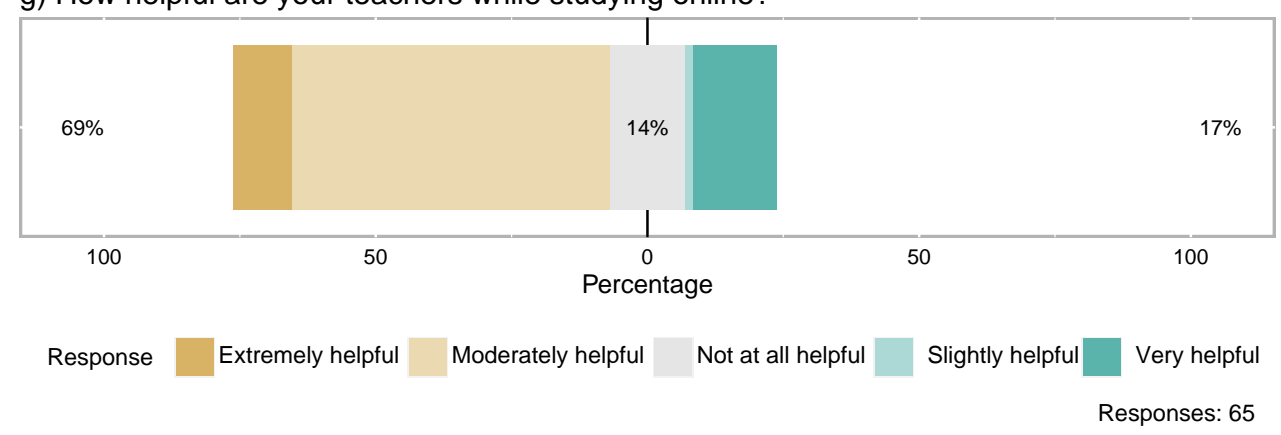

Figure 10. Teachers' helpfulness during the COVID-19 pandemic.

During your remote training, do you use any communication means, such as social media, video chat, etc. to help you communicate with your teachers or classmates? If yes, what is it?

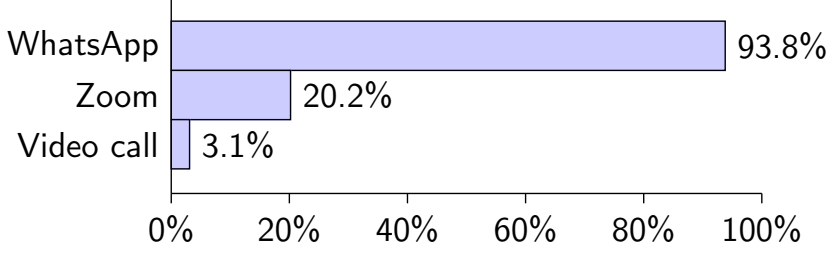

Figure 11. The communication means that students used to communicate with teachers and classmates.

\section{(5) Inadequate support:}

In most cases, deaf students require support in order to assist them in interpreting and understanding content from their teachers. Figure 12 shows the results that we obtained. A large majority of the students indicated that the level and kind of support that they received was not helpful. To interpret their suggestions, P4 said that:

"We do not have an interpreter during COVID-19 as we used before the pandemic. The teacher should have a strong sign language for us to understand them. That is the most crucial thing the deaf needs in learning. The problem we encounter that some teachers sign language is weak. So as a deaf student, if the sign languages were inadequate, there isn't any benefit because the information isn't received correctly and isn't fair."

Even when the interpreters and sign languages were provided, they were not effective in their roles. $\mathbf{P 6}$ explained that:

"Teachers were very close to the device, and I will not be able to see their hands and signs."

We concluded that the students did their best in trying to access the learning platforms but faced challenges due to lack of support. P3 clarified that:

"Many times, we login into the correct lectures, but we cannot find the teacher."

Support for deaf students is critical in the classroom and indispensable in virtual learning. Such students require a lot of assistance, which has not been forthcoming during the COVID-19 pandemic. Even when offered, it has not been adequate. 
h)How helpful your College/University has been in offering you the resources from home?

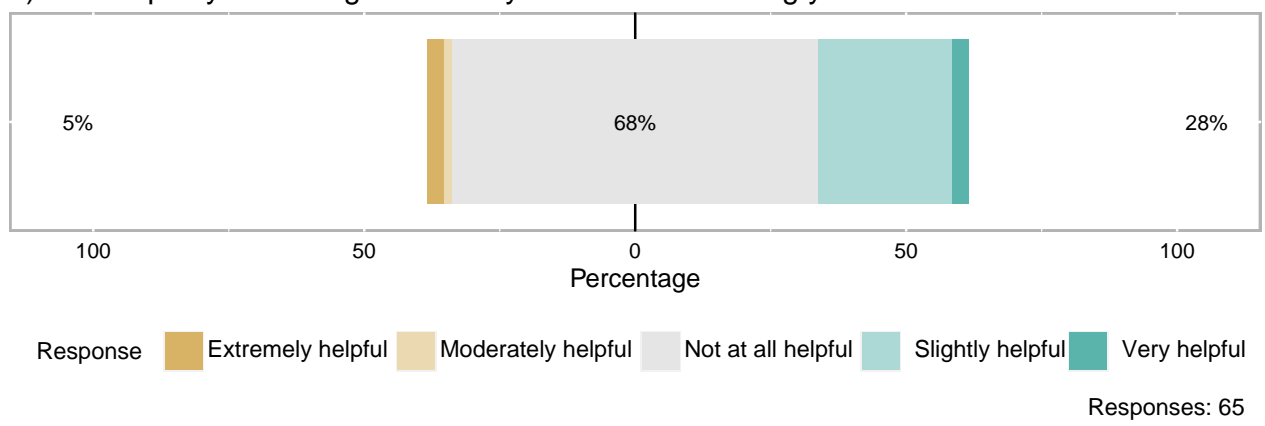

Figure 12. Institute support provided to deaf students.

\section{(6) Technology problems:}

We also wanted to know whether students were satisfied with the software that they were using for learning. Figure 13 shows the results that we obtained. We were surprised that $59(91 \%)$ of the respondents were not satisfied with their online learning, while only $3 \%$ expressed satisfaction. To explain the situation, P2 said that:

"When I encounter problems with the laptop, I switch to access the class through the phone because the internet signal was stronger on my phone than the laptop. When a teacher sends a file during the class, it was not easy to see it through a phone, so I switched back to the laptop. Then, I still struggle to get the file due to the weak internet signal."

The COVID-19 pandemic has created a sudden shift from face-to-face learning to virtual learning, and it seems that many institutions, teachers, and their students were not ready for the change. The challenges have been especially worse for deaf students who require a lot of instructional support in their learning. Such a situation may explain the technological difficulties that they have faced.

i) Are you satisfied with the Blackboard and software you are using for online learning?

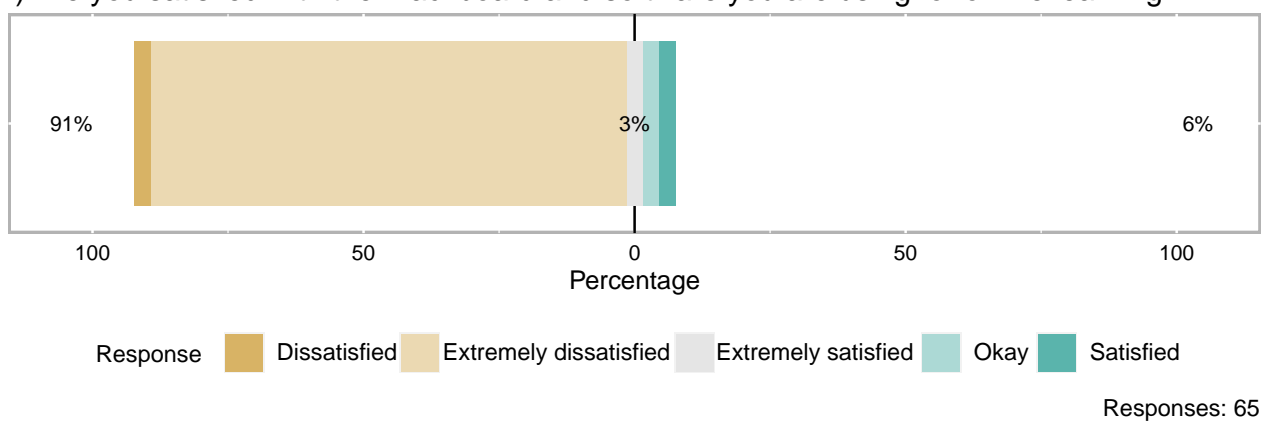

Figure 13. Students satisfaction on Blackboard platform.

\section{(7) Distractions and Time Management Challenge:}

Most of the respondents suggested that their learning during the COVID-19 period was greatly affected by the environment at home. As shown in Figure 14, approximately 51 $(78 \%)$ of the respondents did not have a peaceful time when studying, and the majority of them faced distractions. Such an inconducive environment greatly affected the learning of the respondents at home. 
j) How peaceful is the environment at home while learning online?

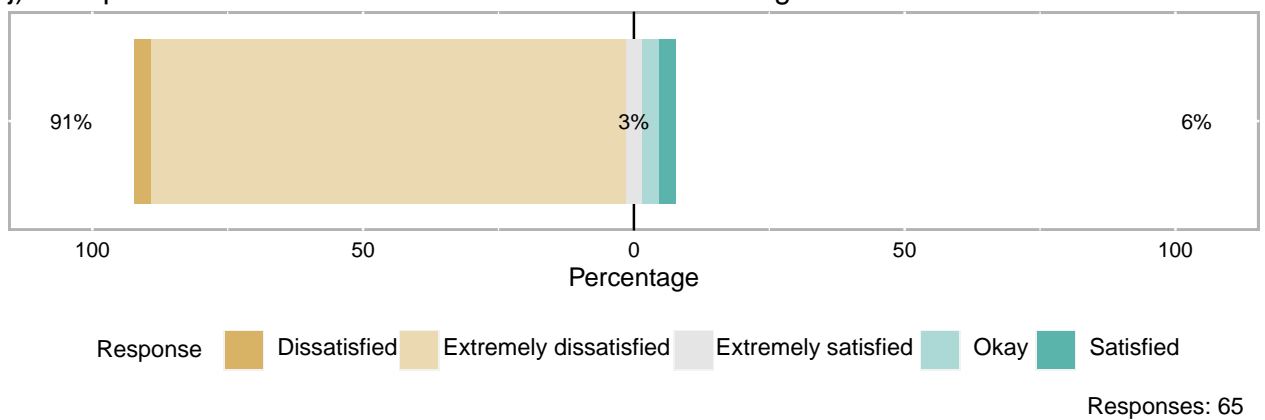

Figure 14. Students environment at home during COVID-19.

Having established that most of the students were distracted while studying from home due to the pandemic, we wanted to find out the types of distractions that they faced. In Figure 15, 56 (86.2\%) of the students were distracted by social media, which is a common issue that affects students' learning in the modern world. Another significant issue was disruption due to the people at home, which was reported by $47(72.3 \%)$ of the respondents. P1 said that:

"It was difficult to manage time at home, and I was anxious. I remember that there were problems between my dad and me, where he kept asking me to do stuff at home while I was trying to study for college. Another issue is that many children were playing around, so half of the time focused on lectures where the other half was being busy with family."

Similar sentiments were also given by the other interviewees, who confirmed that family commitments, as well as disturbance from parents and siblings, also disrupted learning. It was evident that distractions and time management challenges greatly affected the respondents during their studies at home, as Figure 16 indicated $36(55.40 \%)$ of the students had poor time management. We established that the environment was not conducive for them.

What distractions do you face at home?

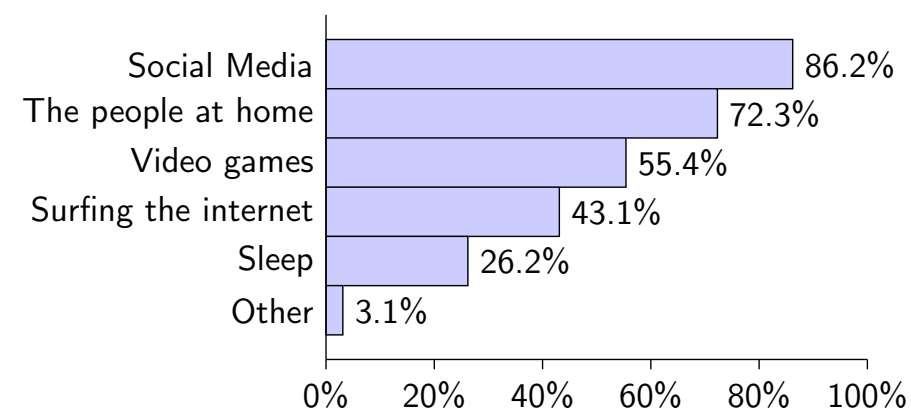

Figure 15. The distractions the deaf students faced. 
How well could you manage time while learning online?

Average

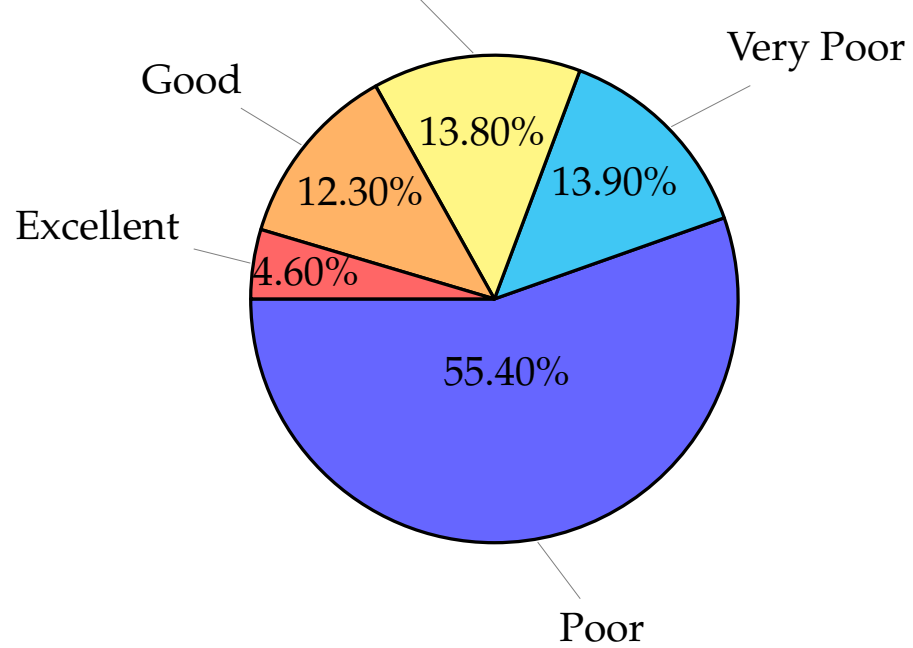

Figure 16. Distribution of student's time management during COVID-9.

\section{Study Discussion}

In this section, we provide the most important takeaways from our study. In total, five takeaways are discussed in the sub-sections below.

Takeaway 1: E-learning limitation. We found that the inadequacy of tools with limited cameras that can be visible to teachers and students posed great challenges to deaf education. The tools do not provide subtitles, and for Zoom, they provide a caption for the stream class, without supporting languages, such as Arabic. Such a finding greatly affected deaf students' learning because they cannot hear what is being said but depend on what they see on the screens. The importance of visual media in education is also indicated by Fernandes et al. [33] in Indonesia, who found that the effective use of videos greatly promoted education. Improvement of such aspects could greatly help in improving deaf education. Future researchers can compare the effectiveness of various e-learning tools to suggest which are more appropriate for deaf students.

Takeaway 2: Lack of experience. It was clear that teachers and students are not trained on the tools or do not even have good documentation to follow. Without such training, there were problems in how both students and teachers used the technology, leading to challenges in education. For deaf students, in particular, have not been trained to use the special tools needed to facilitate their education. Such findings corroborate a similar study by Krishnan et al. [51] in Malaysia that demonstrated issues in e-learning due to a lack of familiarity with technology. Other scholars can investigate the range of training programs, methods, and guidelines that would be useful in enlightening the population on how to undertake online education effectively.

Takeaway 3: Improve the accessibility and usage of learning materials. We noted that there were significant problems in accessibility and usage of learning materials due to reasons such as a lack of subtitles and captions on videos. The importance of improving accessibility for deaf students is confirmed by studies such as Sommer [52] in the US and Mantzikos and Lappa [53] in Greece. It is important to state that deaf students need such assistance in order to understand the content in videos. More research is needed on these accessibility issues in distance/remote education for deaf students to minimize access challenges in similar contexts.

Takeaway 4: Simplify LMS systems. Our findings showed that most students were facing problems navigating through the LMS systems, blackboard in particular. For instance, they 
did not know how to change languages, switch between content, obtain course materials, among others. The problem is worse for deaf students, who cannot follow audio directions on the systems. Such technical issues were also identified by Alsadoon and Turkestani [4] as significant barriers to e-learning for deaf students. It will be important for software engineers to investigate how LMS systems can be simplified for deaf students.

Takeaway 5: Provide necessary equipment and technology. We established that a lot of equipment was needed for students to communicate with their teachers and access materials from the online platforms. For instance, it is important for students to have computers, fast internet access, among other things. The need to provide such tools and technologies was emphasized in a previous study by Krishnan et al. [51]. It will be important to identify how such software and devices can be availed to students.

\section{Limitations and Future Work}

Given the range of effort, direct instruction, and mainstream environments on TVTC, we collected data in order to understand the challenges faced by deaf students. The scope of the study was not to focus on recommendations on how deaf students can best be supported during COVID-19 restrictions or similar circumstances when in a distance learning environment. Future researchers can study the long-term effects of the COVID-19 pandemic and work on coping with the current challenges mentioned in this study. For instance, an organization can set high standards for access to information and monitor educational access for deaf learners. As with every case study, the results may not generalize to other institutions. However, extending this survey with the teachers is part of our future investigation to study the challenges faced by the instructors as well, so technology could be better prepared for the next disaster.

\section{Conclusions}

Understanding the challenges that deaf students faced during the COVID-19 period is of paramount importance to the deaf community. In this work, we aimed to investigate the e-learning experience of 65 deaf students at the Technical and Vocational Training Corporation (TVTC) in Saudi Arabia. Due to the closure of physical classes, online learning using several devices in synchronous (live) and asynchronous (pre-recorded) environments has become an alternative learning method. However, this alternative learning method becomes challenging to deaf students due to the limited resources and accessibility to online learning. In summary, we found that: (1) Blackboard as well as the course material are not easily accessible to the deaf students; (2) deaf students find that learning is extremely stressful during the pandemic; (3) Google Meet is the preferable e-learning tool; (4) communication between deaf students and teachers is ineffective, which impacts the learning outcomes; (5) a lack of support in terms of the provided interpreters hinder the learning process; (6) technology is not always enhanced for people who are deaf or hard of hearing; (7) students who were deaf or hard of hearing had difficulty managing their time due to different types of distractions.

Author Contributions: Conceptualization, W.A., M.W.M. and S.L.; Data curation, W.A., M.A., E.A.A. and Y.B.K.; Formal analysis, W.A., M.A., E.A.A., M.W.M. and Y.B.K.; Funding acquisition, M.W.M.; Investigation, W.A., M.W.M. and S.L.; Methodology, W.A., M.A., E.A.A. and S.L.; Project administration, M.W.M. and S.L.; Resources, M.W.M., S.L. and Y.B.K.; Software, W.A. and S.L.; Supervision, M.W.M. and S.L.; Validation, W.A., M.A., E.A.A., M.W.M., S.L. and Y.B.K.; Visualization, W.A.; Writing-original draft, W.A.; Writing—review \& editing, M.W.M. and S.L. All authors have read and agreed to the published version of the manuscript.

Funding: This research received no external funding.

Institutional Review Board Statement: The study was conducted according to the guidelines of the Technical and Vocational Training Corporation (TVTC) and was approved by the TVTC Research Ethics Committee (protocol code 7/5/48531 and approval date 20/11/2020). 
Informed Consent Statement: For the online survey in this study, a specific section regarding the participants' consent was included. No personal data were collected, and all the data in the survey were anonymized.

Data Availability Statement: Not applicable.

Acknowledgments: We would like to thank the students at TVTC who volunteered their time to participate in this research. Also, we would like to thank the department head of the general administration for research and studies, Eng. Adel Aloud, for his support during the pandemic.

Conflicts of Interest: The authors declare no conflict of interest.

\section{References}

1. Gleason, C.; Valencia, S.; Kirabo, L.; Wu, J.; Guo, A.; Jeanne Carter, E.; Bigham, J.; Bennett, C.; Pavel, A. Disability and the COVID-19 Pandemic: Using Twitter to Understand Accessibility during Rapid Societal Transition. In Proceedings of the 22nd International ACM SIGACCESS Conference on Computers and Accessibility, Virtual Event, 18-22 October 2020; pp. 1-14.

2. Hanjarwati, A.; Suprihatiningrum, J. Is Online Learning Accessible During COVID-19 Pandemic? Voices and Experiences of UIN Sunan Kalijaga Students with Disabilities. Nadwa 2020, 14, 1-38.

3. UNESCO. Including Learners with Disabilities in COVID-19 Education Responses. 2020. Available online: https://en.unesco.or $\mathrm{g} /$ news/including-learners-disabilities-covid-19-education-responses (accessed on 6 August 2021).

4. Alsadoon, E.; Turkestani, M. Virtual Classrooms for Hearing-impaired Students during the COVID-19 Pandemic. Rom. J. Multidimens. Educ. Rom. Pentru Educ. Multidimens. 2020, 12, 1-8.

5. Walabe, E. E-Learning Delivery in Saudi Arabian Universities. Ph.D. Thesis, Université d'Ottawa/University of Ottawa, Ottawa, ON, Canada, 2020.

6. Alahmari, A. The state of distance education in Saudi Arabia. Q. Rev. Distance Educ. 2017, 18, 91-98.

7. Smith, E.E. 3 Things to Consider When Designing Remote Teaching. Mt. R. Univ. 2020. doi: 10.6084/m9.figshare.12125688.v2. [CrossRef]

8. Yezli, S.; Khan, A. COVID-19 social distancing in the Kingdom of Saudi Arabia: Bold measures in the face of political, economic, social and religious challenges. Travel Med. Infect. Dis. 2020, 37, 101692. [CrossRef] [PubMed]

9. Rajab, M.H.; Gazal, A.M.; Alkattan, K. Challenges to online medical education during the COVID-19 pandemic. Cureus 2020, 12, e8966. [CrossRef] [PubMed]

10. AlHumaid, J.; Ali, S.; Farooq, I. The psychological effects of the COVID-19 pandemic and coping with them in Saudi Arabia. Psychol. Trauma Theory Res. Pract. Policy 2020, 12, 505. [CrossRef]

11. Ebrahim, S.H.; Memish, Z.A. Saudi Arabia's drastic measures to curb the COVID-19 outbreak: Temporary suspension of the Umrah pilgrimage. J. Travel Med. 2020, 27, taaa029. [CrossRef]

12. Almekhlafy, S.S.A. Online learning of English language courses via blackboard at Saudi universities in the era of COVID-19: Perception and use. PSU Res. Rev. 2020, 5, 16-32. [CrossRef]

13. Fatani, T.H. Student satisfaction with videoconferencing teaching quality during the COVID-19 pandemic. BMC Med Educ. 2020, 20,1-8. [CrossRef]

14. Alshehri, Y.A.; Mordhah, N.; Alsibiani, S.; Alsobhi, S.; Alnazzawi, N. How the regular teaching converted to fully online teaching in saudi arabia during the coronavirus covid-19. Creat. Educ. 2020, 11, 985-996. [CrossRef]

15. Alqurshi, A. Investigating the impact of COVID-19 lockdown on pharmaceutical education in Saudi Arabia-A call for a remote teaching contingency strategy. Saudi Pharm. J. 2020, 28, 1075-1083. [CrossRef]

16. Madhesh, A. Full exclusion during COVID-19: Saudi Deaf education is an example. Heliyon 2021, 7, e06536. [CrossRef] [PubMed]

17. Alofi, A.S.; Clark, M.D.; Marchut, A.E. Life stories of Saudi deaf individuals. Psychology 2019, 10, 1506. [CrossRef]

18. Al-shammari, M.; Ashankyty, A.; Al-Mowina, N.; Al-Mutairy, N.; Al-shammari, L.; Amin, S. Social-emotional perceptions of deaf students in Hail, Saudi Arabia. Am. J. Educ. Res. 2014, 2, 304-315. [CrossRef]

19. UNESCO-UNEVOC. Technical and Vocational Training Corporation. 2020. Available online: https://unevoc.unesco.org/home /Explore+the+UNEVOC+Network/centre=300 (accessed on 14 August 2021).

20. Özokcu, O.; Yildirim, T. Determining the Fears of Student with Special Needs in Inclusive Environments. Int. Educ. Stud. 2018, 11, 174-182. [CrossRef]

21. Şahin, M. Blended Learning Environment in Vocational Education. In Proceedings of the 5th International Conference on Virtual Learning (ICVL), Targu Mure, Romania, 29-31 October 2010; pp. 244-254.

22. Alebaikan, R. A blended learning framework for Saudi higher education. In Proceedings of the Second International Conference of E-Learning and Distance Learning, Riyadh, Saudi Arabia, 18-20 February 2011.

23. Alaidarous, K.; Madini, A.A. Exploring EFL students' perception in blended learning environment in Saudi technical education context. Int. J. Educ. Investig. 2016, 3, 69-81.

24. Technical and Vocational Training Corporation Learning Center, E-Training. Technical and Vocational Training Corporation. 2021. Available online: http:/ / elearning.edu.sa/ (accessed on 14 August 2021).

25. TVTC. Rayat. 2021. Available online: https://www.tvtc.gov.sa/rayat.html (accessed on 14 March 2021). 
26. Aldiab, A.; Chowdhury, H.; Kootsookos, A.; Alam, F.; Allhibi, H. Utilization of Learning Management Systems (LMSs) in higher education system: A case review for Saudi Arabia. Energy Procedia 2019, 160, 731-737. [CrossRef]

27. Ali, J.K.M. Blackboard as a motivator for Saudi EFL students: A psycholinguistic study. Int. J. Engl. Linguist. 2017, 7, 144-151. [CrossRef]

28. Alturki, U.T.; Aldraiweesh, A. Evaluating the usability and accessibility of LMS "Blackboard" at King Saud University. Contemp. Issues Educ. Res. CIER 2016, 9, 33-44. [CrossRef]

29. Kritzer, K.L.; Smith, C.E. Educating deaf and hard-of-hearing students during COVID-19: What parents need to know. Hearing J. 2020, 73, 32. [CrossRef]

30. Smith, C.; Colton, S. Creating a YouTube Channel to equip parents and teachers of students who are deaf. J. Technol. Teach. Educ. 2020, 28, 453-461.

31. Sutton, H. Guide offers best practices for meeting the needs of deaf students during COVID-19 pandemic. Disabil. Compliance High. Educ. 2020, 26, 9-9. [CrossRef]

32. Lazzari, M.; Baroni, F. Remote teaching for deaf pupils during the Covid-19 emergency. In Proceedings of the 14th International Conference on e-Learning 2020, Lisbon, Portugal, 15-17 December 2020; pp. 170-174.

33. Fernandes, R.; Susilawati, N.; Muspita, R.; Putra, E.V.; Amri, E.; Akbar, A.; Putra, A. Voter Education for The Deaf During The Covid-19 Pandemic. PalArch's J. Archaeol. Egypt/Egyptol. 2020, 17, 10518-10528.

34. Lynn, M.A.; Templeton, D.C.; Ross, A.D.; Gehret, A.U.; Bida, M.; Sanger, T.J.; Pagano, T. Successes and challenges in teaching chemistry to deaf and hard-of-hearing students in the time of COVID-19. J. Chem. Educ. 2020, 97, 3322-3326. [CrossRef]

35. Swanwick, R.; Oppong, A.M.; Offei, Y.N.; Fobi, D.; Appau, O.; Fobi, J.; Frempomaa Mantey, F. The impact of the COVID-19 pandemic on deaf adults, children and their families in Ghana. J. Br. Acad. 2020, 8, 141-165. [CrossRef]

36. Paatsch, L.; Toe, D. The impact of pragmatic delays for deaf and hard of hearing students in mainstream classrooms. Pediatrics 2020, 146, S292-S297. [CrossRef] [PubMed]

37. Tomasuolo, E.; Gulli, T.; Volterra, V.; Fontana, S. The Italian Deaf community at the time of Coronavirus. Front. Sociol. 2021, 5, 125. [CrossRef] [PubMed]

38. Alcazar, V.J.L.L.; Maulana, A.N.M.; Mortega, R.O.; Samonte, M.J.C. Speech-to-visual approach e-learning system for the deaf. In Proceedings of the 2016 11th International Conference on Computer Science \& Education (ICCSE), Nagoya, Japan, 23-25 August 2016; pp. 239-243.

39. Batanero, C.; de Marcos, L.; Holvikivi, J.; Hilera, J.R.; Otón, S. Effects of new supportive technologies for blind and deaf engineering students in online learning. IEEE Trans. Educ. 2019, 62, 270-277. [CrossRef]

40. Batanero-Ochaíta, C.; De-Marcos, L.; Rivera, L.F.; Holvikivi, J.; Hilera, J.R.; Tortosa, S.O. Improving Accessibility in Online Education: Comparative Analysis of Attitudes of Blind and Deaf Students Toward an Adapted Learning Platform. IEEE Access 2021, 9, 99968-99982. [CrossRef]

41. Long, G.L.; Vignare, K.; Rappold, R.P.; Mallory, J. Access to communication for deaf, hard-of-hearing and ESL students in blended learning courses. Int. Rev. Res. Open Distrib. Learn. 2007, 8, 1-13. [CrossRef]

42. Slike, S.B.; Berman, P.D.; Kline, T.; Rebilas, K.; Bosch, E. Providing online course opportunities for learners who are deaf, hard of hearing, or hearing. Am. Ann. Deaf. 2008, 153, 304-308. [CrossRef]

43. Yoon, J.O.; Kim, M. The effects of captions on deaf students' content comprehension, cognitive load, and motivation in online learning. Am. Ann. Deaf. 2011, 156, 283-289. [CrossRef]

44. Burgstahler, S. Opening doors or slamming them shut? Online learning practices and students with disabilities. Soc. Incl. 2015, 3, 69-79. [CrossRef]

45. McKeown, C.; McKeown, J. Accessibility in online courses: Understanding the deaf learner. TechTrends 2019, 63, 506-513. [CrossRef]

46. Counselman Carpenter, E.A.; Meltzer, A.; Marquart, M. Best Practices for Inclusivity of Deaf/deaf/Hard of Hearing Students in the Synchronous Online Classroom. World J. Educ. 2020, 10, 26-34. [CrossRef]

47. Mohammed, N.u.d. Deaf students' linguistic access in online education: The case of Trinidad. Deaf. Educ. Int. 2021, 23, 217-233. [CrossRef]

48. Musyoka, M.M.; Smith, Z.Y. Mainstreamed Deaf/HH Students' Online Learning in K-12: Challenges, Opportunities, and Solutions. In Curriculum Development and Online Instruction for the 21st Century; IGI Global: Hershey, PA, USA, $2021 ;$ pp. 69-89.

49. Long, G.L.; Marchetti, C.; Fasse, R. The importance of interaction for academic success in online courses with hearing, deaf, and hard-of-hearing students. Int. Rev. Res. Open Distrib. Learn. 2011, 12, 1-19. [CrossRef]

50. Caupayan, J.; Pogoy, A. Unheard Stories of Deaf Students in Online Learning: A Phenomenological Study. 2021. Available online: https:/ / papers.ssrn.com/sol3/papers.cfm?abstract_id=3856136 (accessed on 14 August 2021).

51. Krishnan, I.A.; De Mello, G.; Kok, S.A.; Sabapathy, S.K.; Munian, S.; Ching, H.S.; Kandasamy, P.; Ramalingam, S.; Baskaran, S.; Kanan, V.N. Challenges Faced by Hearing Impairment Students During COVID-19. Malays. J. Soc. Sci. Humanit. MJSSH 2020, 5, 106-116. [CrossRef]

52. Sommer, K. The Effect of COVID-19 on Deaf and Hard of Hearing College Students. In 4 Kevin Ung, Director of McNair Scholar's Program; Lee University: Cleveland, TN, USA, 2020; Volume 3, p. 312.

53. Mantzikos, C.N.; Lappa, C.S. Difficulties and Barriers in the Education of Deaf and Hard of Hearing Individuals in the ERA of COVID-19: The Case of Greece-A Viewpoint Article. Eur. J. Spec. Educ. Res. 2020, 6, 75-95. [CrossRef] 
54. Benbasat, I.; Goldstein, D.K.; Mead, M. The case research strategy in studies of information systems. MIS Q. 1987, 11, 369-386. [CrossRef]

55. Zainal, Z. Case study as a research method. Jurnal Kemanusiaan 2007, 5, 1.

56. Goodenough, A.; Waite, S. Real World Research: A resource for Users of Social Research Methods in Applied Settings; John Wiley \& Sons Ltd.: New York, NY, USA, 2011; 586p. [CrossRef]

57. Runeson, P.; Höst, M. Guidelines for conducting and reporting case study research in software engineering. Empir. Softw. Eng. 2009, 14, 131-164. [CrossRef]

58. Kitchenham, B.A.; Pfleeger, S.L. Principles of survey research part 2: Designing a survey. ACM SIGSOFT Softw. Eng. Notes 2002, 27, 18-20. [CrossRef]

59. Boyatzis, R.E. Transforming Qualitative Information: Thematic Analysis and Code Development; Sage: Newcastle upon Tyne, UK, 1998.

60. Roulston, K. Data analysis and 'theorizing as ideology'. Qual. Res. 2001, 1, 279-302. [CrossRef]

61. Braun, V.; Clarke, V. Using thematic analysis in psychology. Qual. Res. Psychol. 2006, 3, 77-101. [CrossRef]

62. Cleminson, J. A thematic analysis of a photo elicitation investigating 'what does it mean to a person to be deaf or hard of hearing?'. J. Appl. Psychol. Soc. Sci. 2019, 5, 1-30.

63. Berke, L.; Seita, M.; Huenerfauth, M. Deaf and hard-of-hearing users' prioritization of genres of online video content requiring accurate captions. In Proceedings of the 17th International Web for All Conference, Taipei, Taiwan, 20-21 April 2020; pp. 1-12.

64. Nowell, L.S.; Norris, J.M.; White, D.E.; Moules, N.J. Thematic analysis: Striving to meet the trustworthiness criteria. Int. J. Qual. Methods 2017, 16, 1609406917733847. [CrossRef]

65. Vaismoradi, M.; Turunen, H.; Bondas, T. Content analysis and thematic analysis: Implications for conducting a qualitative descriptive study. Nurs. Health Sci. 2013, 15, 398-405. [CrossRef] [PubMed]

66. Brenner, M.E. Interviewing in educational research. In Handbook of Complementary Methods in Education Research, 3rd ed.; Routledge: London, UK, 2006; Volume 2, ISBN 9780203874769.

67. Hussein, A. The use of triangulation in social sciences research: Can qualitative and quantitative methods be combined. J. Comp. Soc. Work. 2009, 1, 1-12.

68. Murairwa, S. Voluntary sampling design. Int. J. Adv. Res. Manag. Soc. Sci. 2015, 4, 185-200.

69. N. Alshenaifi, R.; Feng, J.H. Investigating the Use of Social Media in Supporting Children with Cognitive Disabilities and Their Caregivers from Saudi Arabia. In Proceedings of the 22nd International ACM SIGACCESS Conference on Computers and Accessibility, Athens, Greece, 26-28 October 2020; pp. 1-4.

70. Survey Questions. 2021. Available online: https://zenodo.org/record/5638412 (accessed on 2 November 2021).

71. Smith, E.; Loftin, R.; Murphy-Hill, E.; Bird, C.; Zimmermann, T. Improving developer participation rates in surveys. In Proceedings of the 2013 6th International Workshop on Cooperative and Human Aspects of Software Engineering (CHASE), San Francisco, CA, USA, 25 May 2013; pp. 89-92. 